\title{
Fenofibrate improves insulin sensitivity in connection with intramuscular lipid content, muscle fatty acid-binding protein, and $\beta$-oxidation in skeletal muscle
}

\author{
M Furuhashi, N Ura, H Murakami, M Hyakukoku, K Yamaguchi, \\ $\mathrm{K}$ Higashiura and $\mathrm{K}$ Shimamoto
}

Second Department of Internal Medicine, Sapporo Medical University School of Medicine, S-1, W-16, Chuo-ku, Sapporo 060-8543, Japan

(Requests for offprints should be addressed to M Furuhashi; Email: furuhasi@sapmed.ac.jp)

\begin{abstract}
We investigated the effect of fenofibrate, a peroxisome proliferator-activated receptor- $\alpha$ agonist, on insulin sensitivity including lipid metabolism in skeletal muscle. Six-week-old male Sprague-Dawley rats were divided into two groups: those fed a standard chow (control) or a fructose-rich chow (fructose-fed rats (FFRs)) for 6 weeks. FFRs were treated either with a vehicle or with $30 \mathrm{mg} / \mathrm{kg}$ per day of fenofibrate for the last 2 weeks. Insulin sensitivity (M-value) was estimated by the euglycemic hyperinsulinemic glucose clamp method. Fatty acidbinding protein (FABP) in skeletal muscle was measured by ELISA, and the expression of FABP mRNA was analyzed by semi-quantitative RT-PCR. The serum and muscle triglyceride (sTG and $\mathrm{mTG}$ ) levels and the activity of 3-hydroxyacyl-CoA dehydrogenase (HADH), a $\beta$-oxidation enzyme, in muscle were also determined. FFRs showed a lower M-value and higher blood pressure,
\end{abstract}

sTG and mTG than did the control group. The mTG was correlated positively with sTG and negatively with the $\mathrm{M}$-value. Fenofibrate treatment for 2 weeks did not change blood pressure but significantly improved the $\mathrm{M}$-value, sTG and mTG. FABP content and mRNA in the soleus muscle were significantly elevated in FFRs compared with those in the control group. Fenofibrate treatment further increased FABP. The HADH activity was comparable between the control group and FFRs, but significantly increased by fenofibrate treatment. These results suggest that fenofibrate improves insulin sensitivity not only by lowering serum lipids and subsequent influx of fatty acids into muscles but also by reducing intramuscular lipid content via further induction of FABP and stimulation of $\beta$-oxidation in muscles.

Journal of Endocrinology (2002) 174, 321-329

\section{Introduction}

Insulin resistance and accompanying hyperinsulinemia have been reported to play an important role in the onset and progression of hypertension, dyslipidemia and atherosclerosis (Reaven 1988, Kaplan 1989, DeFronzo \& Ferrannini 1991, Iimura 1996). It has also been reported that accumulation of lipid content in skeletal muscle can interfere with insulin action and result in insulin resistance (Storlien et al. 1991, Goodpaster et al. 1997, Pan et al. 1997, Kelley \& Mandarino 2000).

Fatty acid-binding proteins (FABPs) are low-molecularweight cytosolic proteins $(14-15 \mathrm{kDa})$ found in various cell types. The FABP found in skeletal muscle was shown to be identical with heart-type FABP (Peeters et al. 1991). FABPs are thought to play a role in solubilization of long-chain fatty acids and consequently in facilitation of the cytosolic transport of long-chain fatty acids to various intracellular organelles, including the mitochondria, peroxisomes, nucleus and lipid droplets (Storch \&
Thumser 2000). It has been suggested that FABPs are concerned with mitochondrial and peroxisomal $\beta$-oxidation, gene transcription and cell growth/ differentiation, and incorporation of fatty acids into triglyceride (Veerkamp \& van Moerkerk. 1993, Glatz et al. 1995, Borchers et al. 1997, Zanotti 1999).

Peroxisome proliferator-activated receptors (PPARs) are members of the nuclear receptor superfamily, which are involved in gene regulation and are important regulators of glucose and lipid homeostasis (Schoonjans et al. 1997). Whereas thiazolidinediones are insulin sensitizers acting via activation of $\operatorname{PPAR} \gamma$, fibrates exert lipidlowering activity via PPAR $\alpha$. Fibrate treatment regulates lipoprotein metabolism (Staels et al. 1998), fatty acid oxidation (Meertens et al. 1998) and the cellular transport of fatty acids (Motojima et al. 1998) in the liver. Since the $\operatorname{PPAR} \alpha$ protein is also expressed in skeletal muscle as well as in the liver ( $\mathrm{Su}$ et al. 1998), fibrates also seem to be associated with intracellular lipid metabolism in skeletal muscles. It is noteworthy that the promoter of muscle 
FABP has peroxisome proliferator responsive elements (Treuner et al. 1994).

Some studies have shown that fibrates also improved glucose tolerance or increased insulin sensitivity in humans (Jones et al. 1990, Inoue et al. 1994, Yong et al. 1999, Idzior-Walus et al. 2000) and rodents (Matsui et al. 1997, Guerre-Millo et al. 2000, Ye et al. 2001). However, in most of these studies, a gold standard assessment such as the euglycemic hyperinsulinemic glucose clamp method was not used. The mechanisms of these effects are also unclear. We therefore investigated the effect of fenofibrate, a highly selective PPAR $\alpha$ activator, on glucose homeostasis and its relationship to intramuscular lipid content, muscle FABP and muscle $\beta$-oxidation in fructose-fed rats (FFRs) as an animal model of insulin resistance and hypertension.

\section{Materials and Methods}

\section{Protocol 1}

As a preliminary study, 12-week-old male SpragueDawley rats $(n=15)$ obtained from Charles River Japan Inc. (Yokohama, Japan) were used. The care of the animals was in strict accordance with the guiding principles of the Physiological Society of Japan. All rats were fed a standard rat chow containing $60 \%$ vegetable starch, 5\% fat and 24\% protein (Oriental Yeast Co., Tokyo, Japan). They were maintained on a $12 \mathrm{~h}$ light: $12 \mathrm{~h}$ darkness (0700 h-1900 h) cycle and with freely available water and chow. Insulin sensitivity was estimated by the euglycemic hyperinsulinemic glucose clamp method, and soleus muscle was prepared under sodium pentobarbital anesthesia. The lipid content in the soleus muscle was extracted and measured.

\section{Protocol 2}

Animals Male Sprague-Dawley rats of 6 weeks of age were used for all experiments. Prior to any manipulation, all rats were fed standard rat chow. The rats were divided into two groups at the start of the study: those fed a standard rat chow (control group, $n=10$ ) or those given a fructose-rich chow containing 60\% fructose, $5 \%$ fat, and $20 \%$ protein (\#78463; Teklad, WI, USA) for 6 weeks. FFRs were treated by oral gavage either with a vehicle $(2.5 \%$ gum arabic solution; FFR group, $n=10)$ or with $30 \mathrm{mg} / \mathrm{kg}$ per day of fenofibrate (FF), a PPAR $\alpha$-selective agonist (Kaken Pharmaceutical Co., Tokyo, Japan) in $2 \cdot 5 \%$ gum arabic solution (FFR $+\mathrm{FF}$ group, $n=7$ ) for the last 2 weeks. The control group was also treated with the same vehicle by oral gavage during the treatment period.

Blood pressure and pulse rate measurements Systolic blood pressure and pulse rate were measured in all conscious rats using an indirect tail-cuff method (BP-98A; Softran, Tokyo, Japan) on a $37^{\circ} \mathrm{C}$ preheated cloth jacket for $10 \mathrm{~min}$. An average of five recordings was taken as each individual value.

Determination of serum variables Blood samples were collected from the tail vein after $12 \mathrm{~h}$ deprivation of food. Serum was prepared by centrifugation at $2000 \mathrm{~g}$ for $15 \mathrm{~min}$ at $4{ }^{\circ} \mathrm{C}$ and stored at $-20{ }^{\circ} \mathrm{C}$ until use for measurement of serum insulin and lipids. Rat serum insulin was measured with an enzyme immunoassay kit (Morinaga Seikagaku, Yokohama, Japan). Serum levels of triglyceride and free fatty acid were determined by enzymatic colorimetric methods using commercially available test kits (Wako Chemicals, Osaka, Japan) and a U-1100 spectrophotometer (Hitachi Seisakusyo, Tokyo, Japan).

Euglycemic hyperinsulinemic glucose clamp technique At the end of the treatment period, rats were anesthetized i.p. with sodium pentobarbital $(50 \mathrm{mg} / \mathrm{kg})$. The right common carotid artery and the right jugular vein were exposed and cannulated with a polyethylene tube (PE50; Becton Dickinson and Co., Sparks, MD, USA) for collection of blood samples and administration of the infusate respectively. Each rat was placed in a foam plastic jacket that allowed movement of all four limbs and forward vision after overnight fasting (approximately $12 \mathrm{~h}$ ). At the start of the glucose clamp, fasting blood glucose was measured by the glucose oxidase method using an ExacTech 2A glucose analyzer (MediSense, Waltham, MA, USA). The initial load of insulin $(25 \mathrm{mU} / \mathrm{kg}$ of Humalin R, U-40; Shionogi Pharmaceutical Co., Osaka, Japan) was infused by a bolus, and this was followed by a constant infusion of insulin at a rate of $4 \mathrm{mU} / \mathrm{kg}$ per min for $154 \mathrm{~min}$. During the glucose clamp, $12.5 \%$ glucose solution was infused as needed to maintain blood glucose at the fasting level. Ten microliters of arterial blood were sampled at $7 \mathrm{~min}$ intervals for determination of blood glucose. The average of the rate of glucose infusion for the last $35 \mathrm{~min}$ was taken as an index of insulin sensitivity (M-value; $\mathrm{mg} / \mathrm{kg}$ per $\mathrm{min}$ ) (Higashiura et al. 1999).

Tissue preparation Rats were anesthetized i.p. with sodium pentobarbital $(50 \mathrm{mg} / \mathrm{kg})$ and perfused with $150 \mathrm{ml}$ sterile saline through the apex of the left ventricle. Soleus (containing mainly slow-twitch oxidative fibers, type I) and extensor digitorum longus (EDL, containing a mixture of fast-twitch oxidative-glycolytic, type IIa and glycolytic fibers, type IIb) muscles (Ariano et al. 1973) were employed as red and white muscle respectively, and were dissected and immediately frozen in liquid nitrogen. Muscle samples were stored at $-70{ }^{\circ} \mathrm{C}$ until use.

Skeletal muscle triglyceride Total lipid extracts of skeletal muscles were obtained by the method previously 
described (Folch et al. 1957) using 2:1 (v/v) chloroformmethanol. These extracts were then dried under a nitrogen stream, dissolved in 2.0 $\mathrm{ml} \mathrm{100:1} \mathrm{(v/v)} \mathrm{chloroform-acetic}$ acid, and applied to a Sep-Pak Silica cartridge (Waters, Milford, MA, USA) for separation of phospholipids. The fraction including triglyceride was eluted with $14 \mathrm{ml}$ additional 100:1 chloroform-acetic acid (Hamilton \& Comai 1984). A known volume of the fraction was evaporated to dryness using nitrogen. Triglyceride content was determined spectrophotometrically using a test kit as stated above.

Muscle FABP content All steps were performed on ice. Muscles were cut and homogenized $(2 \cdot 5 \%, \mathrm{w} / \mathrm{v})$ in ice-cold PBS ( $\mathrm{pH} 7 \cdot 4)$ using a Polytron (Kinematica, Lucerne, Switzerland). Tissue homogenates were centrifuged at $15000 \mathrm{~g}$ for $15 \mathrm{~min}$ at $4{ }^{\circ} \mathrm{C}$ to remove cell debris. The tissue content of cytosolic FABP was measured with a sandwich ELISA kit (HyCult Biotechnology, Uden, Netherlands) using murine monoclonal IgG antibodies directed against purified FABP. Total protein concentration was determined with a bicinchoninic acid kit (Protein Assay No. 23225; Pierce, Rockford, IL, USA) using BSA as a standard (Smith et al. 1985).

RNA extraction and analysis In all steps of the procedure, $0 \cdot 1 \%$ diethyl pyrocarbonate (DEPC)-treated water was used. Total RNA was isolated according to the modified method as previously described (Chomczynski \& Sacchi 1987) using Trizol reagent (Life Technologies, MD, USA) and dissolved in DEPC-treated water for direct use or stored in $70 \%$ ethanol at $-70{ }^{\circ} \mathrm{C}$. Semiquantitative RT-PCR was performed to assess mRNA expression. The PCR primers used were an oligo (dT) first-strand primer and two pairs of specific primers based on previously reported sequences: $5^{\prime}$-TTGCACCATGG CGGACGCCTTT-3' and 5'-AGTGACGGGGCAGC CAGGTCACGCCTCCTT-3' for muscle FABP (Van Nieuwenhoven et al. 1994), and 5'-CTGATCCACA TCTGCTGGAAGGTGG-3' and $5^{\prime}$-ACCTTCAACAC CCCAGCCATGTACG-3' for $\beta$-actin (Wu et al. 2000) as a housekeeping gene and internal control. The PCR product from an RNA template was obtained with Ready-To-Go RT-PCR Beads (Amersham Pharmacia Biotech, Tokyo, Japan) containing Moloney murine leukemia virus reverse transcriptase and Taq DNA polymerase. The reaction mixture contained $2 \mu \mathrm{g}$ total RNA, the first-strand primer, one pair of specific primers, and DEPC-treated water in a total volume of $50 \mu \mathrm{l}$. A one-step protocol for RT-PCR was performed using a PCR Thermal Cycler SP (TP400; Takara Shuzo Co., Shiga, Japan) according to the following scheme: (i) 15 min first-strand synthesis at $42{ }^{\circ} \mathrm{C}$; (ii) 5 min inactivation of reverse transcriptase and denaturation at $95^{\circ} \mathrm{C}$; (iii) optimized cycles depending on the target (FABP of the soleus, 16 cycles; FABP of the EDL, 22 cycles; $\beta$-actin of both muscles, 22 cycles) of $30 \mathrm{~s}$ at $95^{\circ} \mathrm{C}$ (denaturation), $30 \mathrm{~s}$ at $59^{\circ} \mathrm{C}$ (annealing), $30 \mathrm{~s}$ at $72^{\circ} \mathrm{C}$ (elongation); and (iv) finally $7 \mathrm{~min}$ at $72^{\circ} \mathrm{C}$ (final extension). Preliminary experiments confirmed that each PCR product was performed within the linear phase of the PCR amplified reaction. Each sample was electrophoresed on 1.5\% agarose gel and stained with ethidium bromide. The intensity of the ethidium bromide luminescence was detected by charge coupled device (CCD) imaging (COMPACT BIS; Amersham Pharmacia Biotech) and analyzed using SigmaGel software (SPSS Inc., Chicago, IL, USA).

Enzymatic activities Activities of 3-hydroxyacyl-CoA dehydrogenase (HADH, EC 1.1.1.35) and citrate synthase (EC 4.1.3.7) were measured spectrophotometrically at $37^{\circ} \mathrm{C}$ in supernatants of muscle homogenates (Osumi \& Hashimoto 1979, Srere 1969). Enzyme activities are expressed in $\mu \mathrm{mol} / \mathrm{min}$ per $\mathrm{g}$ wet weight of tissue.

Statistical analysis All numeric variables are expressed as means \pm S.E.M. Group statistical comparisons were assessed by one-way ANOVA and individual comparisons by Fisher post hoc tests. Regression analyses were used to compare relationships. A $P$ value of $<0 \cdot 05$ was considered statistically significant.

\section{Results}

\section{Protocol 1}

Intramuscular triglyceride content in the soleus muscle of Sprague-Dawley rats $(n=15)$ was negatively correlated with the $M$-value as an index of insulin sensitivity $(r=-0 \cdot 67, P<0 \cdot 05$; Fig. 1).

\section{Protocol 2}

Physical and biochemical findings (Table 1) There were no inter-group differences in body weight, pulse rate and fasting blood glucose. Systolic blood pressure was significantly higher in FFRs than in control rats. The average rate of glucose infusion during the last $35 \mathrm{~min}$ of the glucose clamp, as an index of insulin sensitivity (M-value), was significantly lower in FFRs than in control rats. Fenofibrate treatment for 2 weeks did not change blood pressure in FFRs but significantly improved the $\mathrm{M}$-value in FFRs. A high fructose diet significantly increased serum insulin, triglyceride and free fatty acid levels. Fenofibrate treatment essentially reversed the serum insulin and lipids concentrations. In particular, the serum triglyceride was significantly lower in the FFR +FF group than in the FFR and control groups.

Muscle triglyceride content FFRs showed a significant increase in the triglyceride content of the soleus muscle 


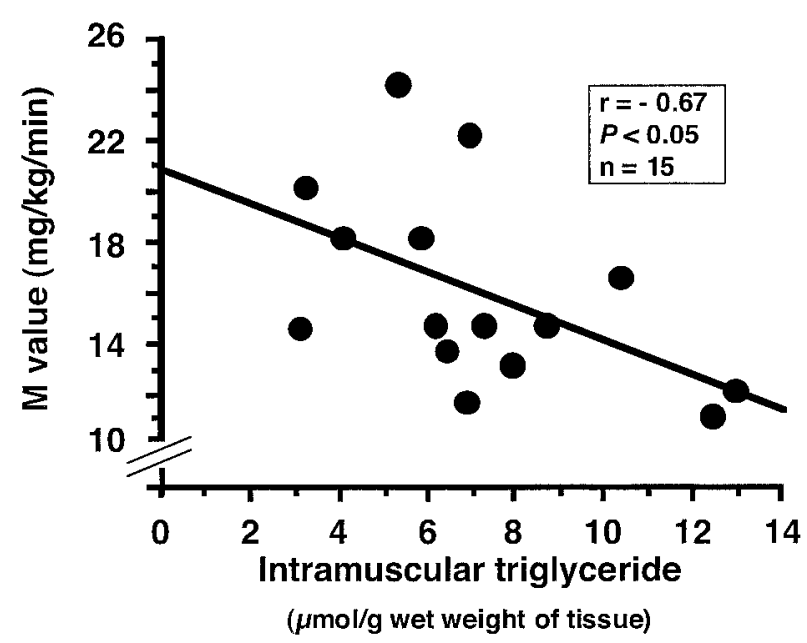

Figure 1 Negative correlation between intramuscular triglyceride level and the M-value in Sprague-Dawley rats. The M-value as an index of insulin sensitivity was estimated by the euglycemic hyperinsulinemic glucose clamp method. Intramuscular triglyceride level was measured in the soleus muscle.

compared with that in the control group (Fig. 2A). Both serum triglyceride and free fatty acid levels were significantly correlated with the triglyceride content in the soleus muscle (Fig. 3). The lipid content of the EDL muscle in FFRs maintained its tendency to be higher than that in the control group $(5 \cdot 8 \pm 1 \cdot 0$ and $8 \cdot 6 \pm 1 \cdot 1 \mu \mathrm{mol} / \mathrm{g}$ wet weight of tissue for the control and FFR groups respectively, $P=0 \cdot 06$; Fig. 2B). Fenofibrate treatment recovered the intramuscular triglyceride to the same level as that of the control group.

FABP in muscle tissue Cytosolic FABP content of the soleus muscle was significantly elevated in FFRs compared with that in the control rats $(2 \cdot 3 \pm 0 \cdot 1$ and $3 \cdot 1 \pm 0 \cdot 2 \mathrm{mg} / \mathrm{g}$ protein for the control and FFR groups respectively, $P<0 \cdot 05)$. Fenofibrate treatment further increased the FABP content of the soleus muscle $(5 \cdot 3 \pm 0.5 \mathrm{mg} / \mathrm{g}$
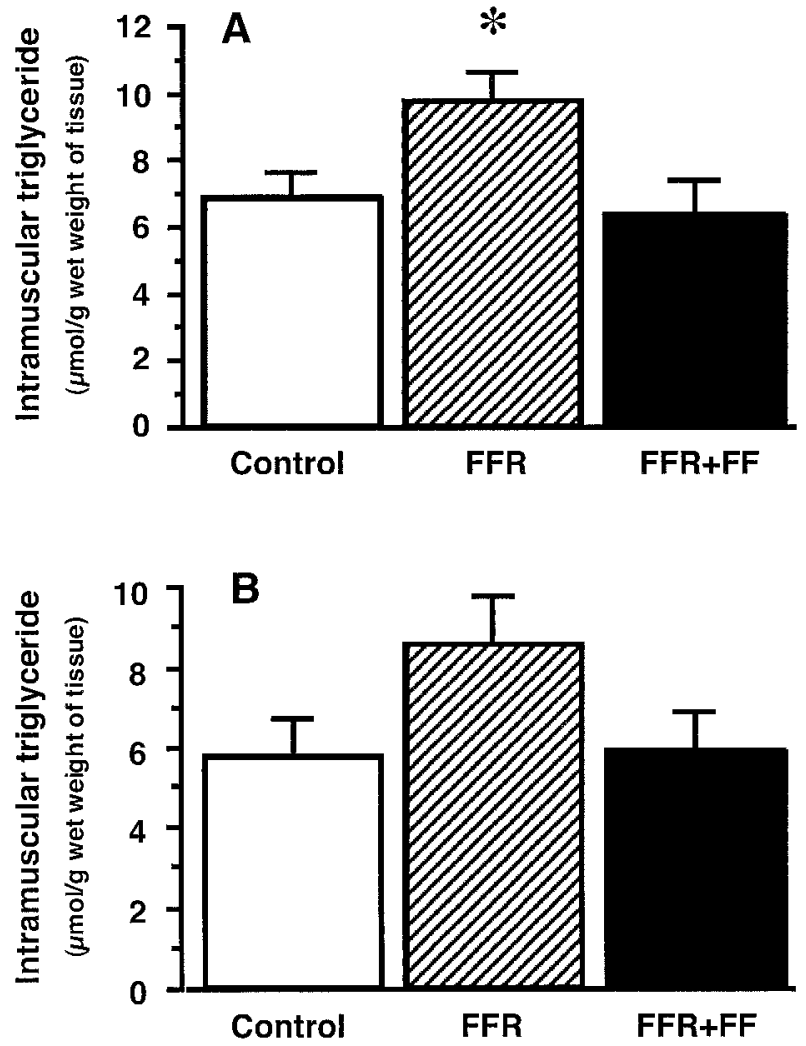

Figure 2 Intramuscular triglyceride levels in the soleus (A) and extensor digitorum longus (EDL) $(B)$ muscles in the control group $(n=10)$, fructose-fed rats (FFR) group $(n=10)$, and FFR+

fenofibrate (FF) group $(n=7)$. The triglyceride content of the soleus muscle in FFRs was significantly higher than that in control rats, whereas that of the EDL tended to be higher in FFRs. FF treatment reduced the intramuscular triglyceride content to the control level. Values are means \pm S.E.M. ${ }^{*} P<0 \cdot 01$ vs control and FFR $+F F$.

protein, $P<0 \cdot 01$ vs other groups; Fig. 4 A). The FABP content of the soleus muscle was approximately 4-fold higher than that of the EDL muscle in the control group.

Table 1 Physical and biochemical characteristics of rats at 12 weeks of age. Values are means \pm S.E.M.

\begin{tabular}{|c|c|c|c|}
\hline & $\begin{array}{l}\text { Control } \\
(n=10)\end{array}$ & $\begin{array}{l}\text { FFR } \\
(n=10)\end{array}$ & $\begin{array}{l}\mathbf{F F R}+\mathbf{F F} \\
(n=7)\end{array}$ \\
\hline \multicolumn{4}{|l|}{ Variables } \\
\hline Body weight (g) & $384 \pm 5$ & $388 \pm 4$ & $388 \pm 10$ \\
\hline Systolic blood pressure $(\mathrm{mmHg})$ & $127 \pm 2$ & $137 \pm 2^{*}$ & $136 \pm 2^{*}$ \\
\hline Pulse rate (beats/min) & $329 \pm 7$ & $329 \pm 8$ & $317 \pm 6$ \\
\hline $\mathrm{M}$-value (mg/kg per min) & $16 \cdot 3 \pm 0 \cdot 8$ & $12 \cdot 4 \pm 1 \cdot 1^{*}$ & $15 \cdot 9 \pm 0 \cdot 9^{\S}$ \\
\hline Fasting blood glucose $(\mathrm{mmol} / \mathrm{l})$ & $4 \cdot 7 \pm 0 \cdot 2$ & $5 \cdot 0 \pm 0 \cdot 2$ & $5 \cdot 1 \pm 0 \cdot 1$ \\
\hline Fasting insulin $(\mathrm{pmol} / \mathrm{l})$ & $128 \pm 24$ & $343 \pm 31^{*}$ & $107 \pm 23^{\ddagger}$ \\
\hline Triglyceride $(\mathrm{mmol} / \mathrm{l})$ & $1 \cdot 34 \pm 0 \cdot 11$ & $2 \cdot 55 \pm 0 \cdot 27^{*}$ & $0 \cdot 68 \pm 0.05^{\dagger, \neq}$ \\
\hline Free fatty acid $(\mathrm{mmol} / \mathrm{l})$ & $1 \cdot 23 \pm 0 \cdot 07$ & $1 \cdot 53 \pm 0.06^{*}$ & $1 \cdot 03 \pm 0 \cdot 07^{\ddagger}$ \\
\hline
\end{tabular}



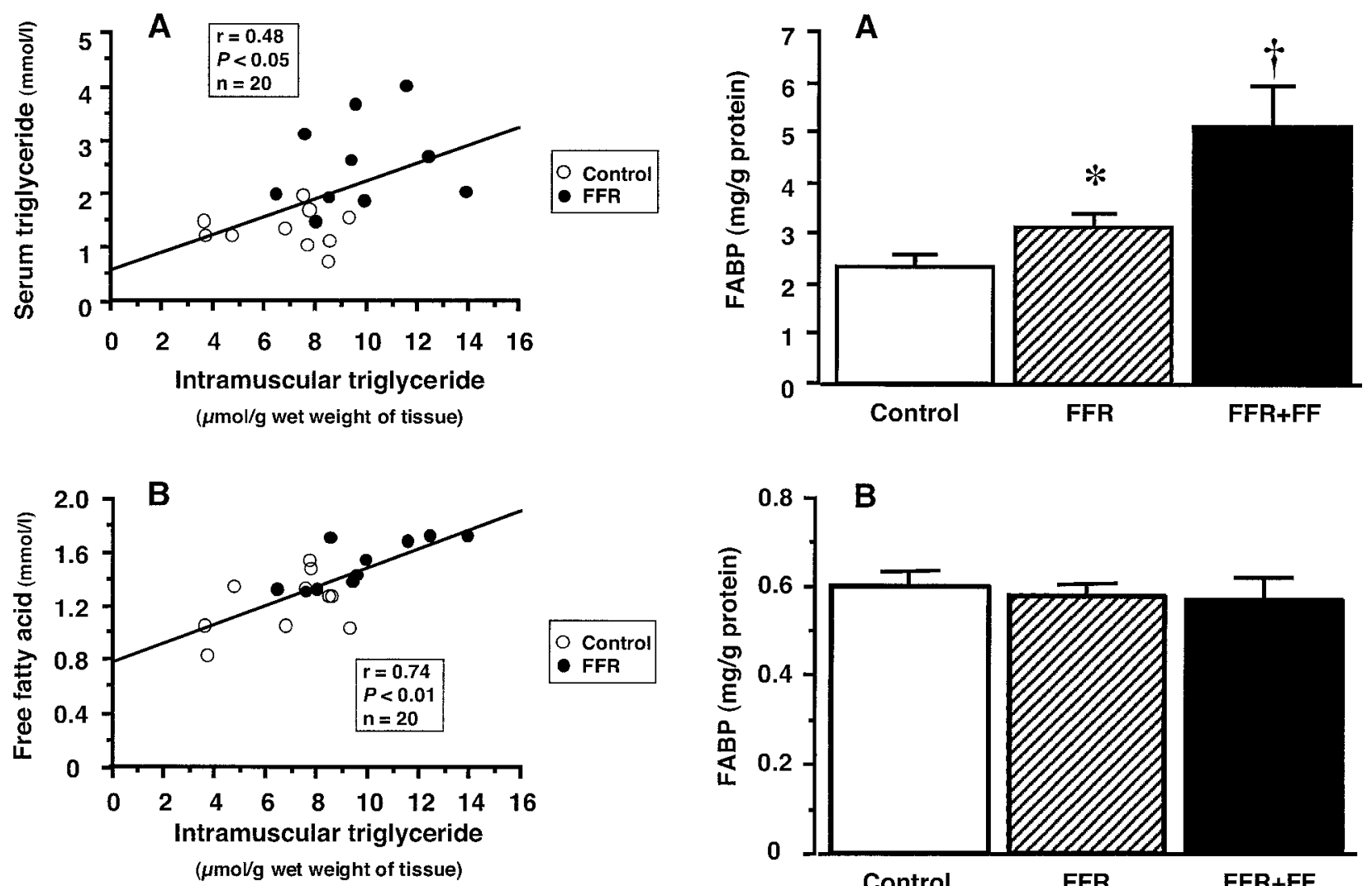

Figure 3 Positive correlation between triglyceride content of the soleus muscle and serum triglyceride (A) or free fatty acid (B) in both the control group $(n=10)$ and FFR group $(n=10)$.

No significant inter-group difference in the FABP content of the EDL muscle was observed (Fig. 4B). The expression of FABP mRNA analyzed by RT-PCR was similar to that of FABP protein in each muscle (Fig. 5).

Enzymatic activities (Table 2) The activities of the $\beta$-oxidation enzyme HADH in both muscles were comparable in the control and FFR groups. Fenofibrate increased HADH activity significantly in the soleus muscle $(11.5 \pm 0.5$ and $16.6 \pm 1.3 \mu \mathrm{mol} / \mathrm{min}$ per g wet weight of tissue in the FFR and FFR + FF groups respectively, $P<0 \cdot 01)$, but not in the EDL muscle $(4 \cdot 1 \pm 0 \cdot 4$ and $5 \cdot 4 \pm 0.6 \mu \mathrm{mol} / \mathrm{min}$ per $\mathrm{g}$ wet weight of tissue in the FFR and FFR +FF groups respectively, $P=0 \cdot 07$ ). The activity of the mitochondrial enzyme citrate synthase in muscles was not significantly different among the three groups. The soleus muscle exhibited greater $\mathrm{HADH}$ and citrate synthase activities than did the EDL.

\section{Discussion}

There are few reports on the effects of fibrates (PPAR $\alpha$ agonists) on insulin sensitivity. Some studies have

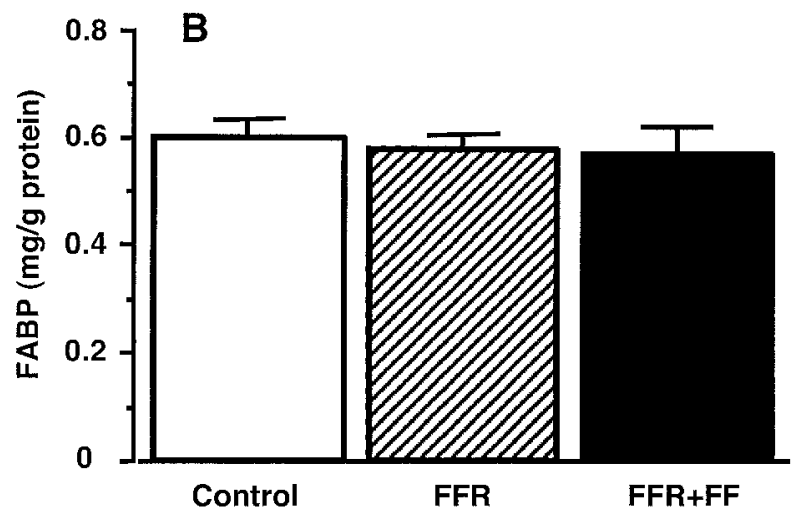

Figure 4 Muscle fatty acid-binding protein (FABP) levels in the soleus (A) and EDL (B) muscles in the control group $(n=10)$, FFR group $(n=10)$ and FFR + FF group $(n=7)$. FABP was measured by ELISA. (A) Muscle FABP was elevated by high fructose diet and further induced by FF treatment in the soleus muscle. (B) No significant difference in muscle FABP was observed among the three groups in the EDL muscle. Values are means \pm S.E.M. ${ }^{\star} P<0 \cdot 01$ vs control; ${ }^{\dagger} P<0.01$ vs control and FFRs.

demonstrated that bezafibrate normalized impaired glucose tolerance in both human and rodent models of insulin resistance (Jones et al. 1990, Inoue et al. 1994, Matsui et al. 1997). However, bezafibrate activates $\operatorname{PPAR} \alpha, \operatorname{PPAR} \gamma$ and $\operatorname{PPAR} \delta$ with almost comparable EC $_{50}$ values (PPAR $\alpha$ : 50; PPAR $\gamma$ : 60; PPAR $\delta: 20 \mu \mathrm{M}$ in humans, PPAR $\alpha$ : 90; PPAR $\gamma$ : 55; PPAR $\delta$ : $110 \mu \mathrm{M}$ in rodents, for reference see Brown et al. (1999)). Therefore, it is impossible to conclude that PPAR $\alpha$ activation improves glucose metabolism, since $\operatorname{PPAR} \gamma$ agonists are known to be insulin sensitizers. In the present study, fenofibrate was used as a PPAR $\alpha$-selective fibrate (PPAR $\alpha$ : 18; PPAR $\gamma$ : 250; PPAR $\delta:>300 \mu \mathrm{M}$, for reference see Brown et al. (1999)). Although small-scale studies using human subjects have shown that fenofibrate increased insulin sensitivity as assessed by oral glucose tolerance tests and the serum insulin level (Yong et al. 1999, Idzior-Walus et al. 2000), the mechanisms remain unclarified. Recently, it has been reported that selective 

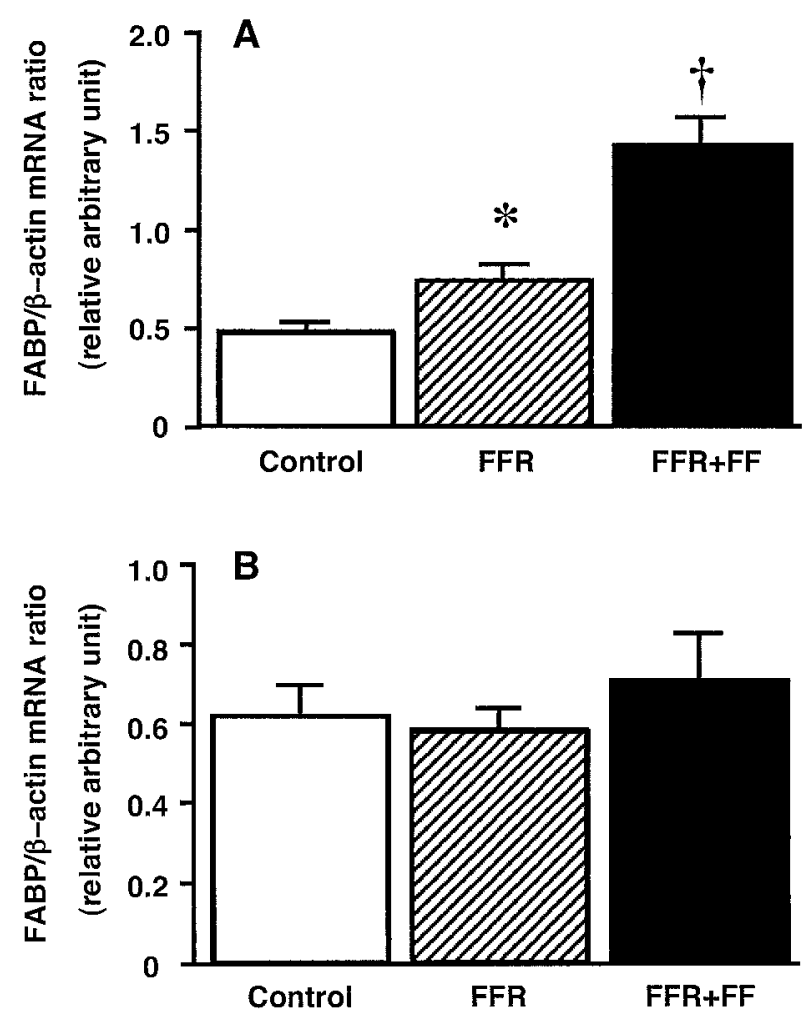

Figure 5 Muscle FABP mRNA expression in the soleus (A) and EDL (B) muscles in the control group $(n=8)$, FFR group $(n=8)$ and FFR + FF group $(n=6)$. FABP and $\beta$-actin (as an internal control) mRNA were analyzed by semi-quantitative RT-PCR. (A) Muscle FABP mRNA in the soleus muscle was significantly elevated in the FFR group compared with that in the control group and further induced in the FFR+FF group. (B) No significant difference in muscle FABP mRNA was observed among the three groups in the EDL muscle. Values are means \pm S.E.M. ${ }^{*} P<0 \cdot 05$ vs control; ${ }^{\dagger} P<0 \cdot 01$ vs control and FFRs.

PPAR $\alpha$ agonists such as fenofibrate and Wy14,643 inhibited high fat diet-induced insulin resistance concomitantly with prevention of high fat diet-induced increase in body weight and adipose tissue mass in rodents (GuerreMillo et al. 2000, Ye et al. 2001). It is unclear, however, whether the effect of PPAR $\alpha$ agonists on insulin sensitiv- ity is a direct action or a secondary action due to a decrease in body weight and adiposity. We therefore used FFRs as a non-obese insulin-resistant hypertension model (Hwang et al. 1987, Reaven et al. 1988) and correctly assessed insulin sensitivity by the euglycemic hyperinsulinemic glucose clamp method. The results showed that fenofibrate increased the M-value in FFRs, indicating an improvement in insulin sensitivity without influencing body weight as well as fat mass weight (data not shown).

Skeletal muscle plays important roles not only in insulin-mediated glucose metabolism, which accounts for more than $80 \%$ of whole body glucose disposal (DeFronzo et al. 1981), but also in the catabolism of fatty acids (Dagenais et al. 1976). Studies in rats and humans have shown that muscle triglyceride content is negatively related to insulin action (Storlien et al. 1991, Goodpaster et al. 1997, Pan et al. 1997, Kelley \& Mandarino 2000). This finding was also confirmed in the present study (Fig. 1). A high fructose diet for 6 weeks increased muscle triglyceride content, which was correlated with serum lipids, and might cause insulin resistance together with previously reported mechanisms such as an alteration of muscle fiber composition (Higashiura et al. 1999) and increased tumor necrosis factor- $\alpha$ in skeletal muscle (Togashi et al. 2000). Fenofibrate treatment for 2 weeks might improve insulin sensitivity by lowering muscle triglyceride content in FFRs.

PPAR $\alpha$ is highly expressed in the liver, and fibrates exert lipid-lowering activity via activation of $\operatorname{PPAR} \alpha$, leading to altered expression of genes involved in lipid and lipoprotein metabolism in the liver (Staels et al. 1998). A possible mechanism of the improvement in insulin sensitivity by fenofibrate may be a decrease in influx of fatty acids into muscles via a decrease in circulating lipids. In addition, since Wy14,643, a PPAR $\alpha$ agonist, increases total glucose incorporation into both glycogen and lipids in the liver (Ye et al. 2001), the liver may be another important site of glucose disposal induced by PPAR $\alpha$ stimulation.

In general, the tissue $\mathrm{FABP}$ content is related to the rate of fatty acid uptake and/or utilization (Glatz et al. 1995). Furthermore, manipulations that will change the rate of tissue fatty acid metabolism appear to be associated with

Table 2 Activities of metabolic enzymes in skeletal muscles. Values are means \pm S.E.M.

\begin{tabular}{|c|c|c|c|c|}
\hline & \multicolumn{2}{|c|}{$\begin{array}{l}\text { HADH } \\
(\mu \mathrm{mol} / \mathrm{min} \text { per } \mathrm{g} \text { wet tissue })\end{array}$} & \multicolumn{2}{|c|}{$\begin{array}{l}\text { Citrate synthase } \\
(\mu \mathrm{mol} / \mathrm{min} \text { per } \mathrm{g} \text { wet tissue })\end{array}$} \\
\hline & Soleus & $\mathrm{EDL}$ & Soleus & $\mathrm{EDL}$ \\
\hline \multicolumn{5}{|l|}{ Treatment } \\
\hline Control $(n=10)$ & $11 \cdot 8 \pm 1 \cdot 0$ & $4 \cdot 4 \pm 0 \cdot 5$ & $23 \cdot 3 \pm 3 \cdot 2$ & $9 \cdot 0 \pm 1 \cdot 8$ \\
\hline $\operatorname{FFR}(n=10)$ & $11 \cdot 5 \pm 0 \cdot 5$ & $4 \cdot 1 \pm 0 \cdot 4$ & $21 \cdot 0 \pm 3 \cdot 0$ & $8 \cdot 2 \pm 1 \cdot 4$ \\
\hline $\mathrm{FFR}+\mathrm{FF}(n=7)$ & $16 \cdot 6 \pm 1 \cdot 3^{*}$ & $5 \cdot 4 \pm 0 \cdot 6$ & $35 \cdot 0 \pm 7 \cdot 5$ & $11 \cdot 2 \pm 2 \cdot 5$ \\
\hline
\end{tabular}


concomitant changes in FABP content. A high dietary fat content increased liver-type FABP in the liver and heart-type FABP in the heart (Glatz et al. 1995). It has also been reported that the content of heart-type FABP in the rat heart (Glatz et al. 1994) and red muscle (Carey et al. 1994) was increased in streptozotocin-induced diabetic rats known to increase fatty acid utilization. In the present study, a high fructose diet increased serum triglyceride and free fatty acid levels and also induced muscle FABP content in the soleus muscle. Elevated muscle FABP may facilitate the transport of fatty acids to mitochondria and the catabolism of fatty acids in skeletal muscle (Storch \& Thumser 2000). It seems that excess influx of fatty acids into muscles causes accumulation of muscle lipid content because of insufficient elevation of muscle FABP.

PPAR $\alpha$ is highly expressed in tissues with elevated rates of fatty acid catabolism, where it regulates genes involved in fatty acid intake, activation into acyl-CoA esters, degradation via the mitochondrial and peroxisomal $\beta$-oxidation pathways and ketone body synthesis (Schoonjans et al. 1997). Fibrates induce liver-type FABP (Kaikaus et al. 1993) and $\beta$-oxidation enzyme $\mathrm{HADH}$ (Zhang et al. 1992) via PPAR $\alpha$ activation. PPAR $\alpha$ protein is also expressed in skeletal muscle as well as in the liver (Su et al. 1998). The promoter of heart-type FABP (equal to muscle FABP) has peroxisome proliferator responsive elements (Treuner et al. 1994) as well as that of liver-type FABP (Issemann et al. 1992) and HADH (Zhang et al. 1992). It has also been reported that heart-type FABP is expressed in skeletal muscle and induced by Wy14,643, a $\operatorname{PPAR} \alpha$ activator, suggesting that the gene is regulated by $\operatorname{PPAR} \alpha$ (Motojima 2000). We found fenofibrate induced red muscle FABP at the transcriptional level.

It is presumed that FABPs serve as intracellular buffers of fatty acids, protecting cells from deleterious effects of excess free fatty acids by sequestering them inside the ligand cavity (Bernlohr et al. 1997). This could include a more specific role in scavenging of excess intracellular lipid content. The present study demonstrated that fenofibrate increased FABP in oxidative red muscle, probably facilitating the transport of fatty acids to mitochondria, and stimulated $\beta$-oxidative degradation of fatty acids. Scavenging of intracellular fatty acids in muscle might lead to a decrease in intramuscular triglyceride and result in improved insulin sensitivity.

The effects of fenofibrate on FABP in the soleus (red) and EDL (white) muscles were different in the present study. Red skeletal muscle (containing mainly slow-twitch oxidative fibers) differs from white skeletal muscle (containing fast-twitch glycolytic fibers) in several ways, including capillary density, oxidative enzyme content and mitochondria density. These inherent characteristics of red muscle account for its overall higher respiratory capacity and ability to oxidize fatty acids. Previous assessment of muscle FABP expression suggests that the levels of both protein and mRNA correspond to the oxidative fiber-type content in a given muscle (Peeters et al. 1991). It was also reported that red, but not white, muscle FABP was modulated in streptozotocin-induced diabetic rats known to increase fatty acid utilization (Carey et al. 1994). The modulation of muscle FABP may be predominant in red muscle compared with white muscle.

Previous reports showed that $\operatorname{PPAR} \alpha$ agonists such as bezafibrate ( $\mathrm{Si}$ et al. 1999, Jonkers et al. 2001) and fenofibrate (Yong et al. 1999, Idzior-Walus et al. 2000) reduced blood pressure. It is speculated that this blood pressure-lowering effect is due to an enhancement of insulin sensitivity or an improvement in endothelial function. In the present study, fenofibrate treatment for 2 weeks improved insulin sensitivity but did not influence blood pressure. This discrepancy is probably due to the treatment period, which was shorter in the present study than in the previous studies (6-24 weeks). It was also reported that TSJN, a Chinese medicine used to treat diabetes mellitus, attenuated blood pressure in FFRs treated for 4 weeks but not those treated for 2 weeks despite improvement in insulin sensitivity (Li et al. 2000). Taking this point into consideration, fenofibrate treatment for 2 weeks seems to be sufficient to ameliorate insulin resistance but not to reduce blood pressure.

In conclusion, the results from this study suggest that fenofibrate improves insulin sensitivity not only by lowering serum lipids and subsequent influx of fatty acids into muscles but also by reducing intramuscular lipid content via further induction of FABP and stimulation of $\beta$-oxidation in muscles.

\section{References}

Ariano MA, Armstrong RB \& Edgerton VR 1973 Hindlimb muscle fiber populations of five mammals. Journal of Histochemistry and Cytochemistry 21 51-55.

Bernlohr DA, Simpson MA, Hertzel AV \& Banaszak LJ 1997 Intracellular lipid-binding proteins and their genes. Annual Review of Nutrition 17 277-303.

Borchers T, Hohoff C, Buhlmann C \& Spener F 1997 Heart-type fatty acid binding protein - involvement in growth inhibition and differentiation. Prostaglandins, Leukotrienes and Essential Fatty Acids $\mathbf{5 7}$ 77-84.

Brown PJ, Winegar DA, Plunket KD, Moore LB, Lewis MC, Wilson JG, Sundseth SS, Koble CS, Wu Z, Chapman JM, Lehmann JM, Kliewer SA \& Willson TM 1999 A ureido-thioisobutyric acid (GW9578) is a subtype-selective PPAR $\alpha$ agonist with potent lipid-lowering activity. Journal of Medicinal Chemistry 42 3785-3788.

Carey JO, Neufer PD, Farrar RP, Veerkamp JH \& Dohm GL 1994 Transcriptional regulation of muscle fatty acid-binding protein. Biochemical Journal 298 613-617.

Chomczynski P \& Sacchi N 1987 Single-step method of RNA isolation by acid guanidinium thiocyanate-phenol-chloroform extraction. Analytical Biochemistry 162 156-159.

Dagenais GR, Tancredi RG \& Zierler KL 1976 Free fatty acid oxidation by forearm muscle at rest, and evidence for an intramuscular lipid pool in the human forearm. Journal of Clinical Investigation $\mathbf{5 8}$ 421-431.

DeFronzo RA \& Ferrannini E 1991 Insulin resistance. A multifaceted syndrome responsible for NIDDM, obesity, hypertension, 
dyslipidemia, and atherosclerotic cardiovascular disease. Diabetes Care 14 173-194.

DeFronzo RA, Jacot E, Jequier E, Maeder E, Wahren J \& Felber JP 1981 The effect of insulin on the disposal of intravenous glucose. Results from indirect calorimetry and hepatic and femoral venous catheterization. Diabetes 30 1000-1007.

Folch J, Lees M \& Sloane Stanley GH 1957 A simple method for the isolation and purification of total lipids from animal tissues. Journal of Biological Chemistry 226 497-509.

Glatz JF, van Breda E, Keizer HA, de Jong YF, Lakey JR, Rajotte RV, Thompson A, van der Vusse GJ \& Lopaschuk GD 1994 Rat heart fatty acid-binding protein content is increased in experimental diabetes. Biochemical and Biophysical Research Communications 199 639-646.

Glatz JF, Borchers T, Spener F \& van der Vusse GJ 1995 Fatty acids in cell signalling: modulation by lipid binding proteins. Prostaglandins, Leukotrienes and Essential Fatty Acids 52 121-127.

Goodpaster BH, Thaete FL, Simoneau JA \& Kelley DE 1997 Subcutaneous abdominal fat and thigh muscle composition predict insulin sensitivity independently of visceral fat. Diabetes $\mathbf{4 6}$ 1579-1585.

Guerre-Millo M, Gervois P, Raspe E, Madsen L, Poulain P, Derudas B, Herbert JM, Winegar DA, Willson TM, Fruchart JC, Berge RK \& Staels B 2000 Peroxisome proliferator-activated receptor $\alpha$ activators improve insulin sensitivity and reduce adiposity. Journal of Biological Chemistry 275 16638-16642.

Hamilton JG \& Comai K 1984 Separation of neutral lipids and free fatty acids by high-performance liquid chromatography using low wavelength ultraviolet detection. Journal of Lipid Research $\mathbf{2 5}$ $1142-1148$

Higashiura K, Ura N, Takada T, Agata J, Yoshida H, Miyazaki Y \& Shimamoto K 1999 Alteration of muscle fiber composition linking to insulin resistance and hypertension in fructose-fed rats. American Journal of Hypertension 12 596-602.

Hwang IS, Ho H, Hoffman BB \& Reaven GM 1987 Fructose-induced insulin resistance and hypertension in rats. Hypertension 10 512-516.

Idzior-Walus B, Sieradzki J, Rostworowski W, Zdzienicka A, Kawalec E, Wojcik J, Zarnecki A \& Blane G 2000 Effects of comicronised fenofibrate on lipid and insulin sensitivity in patients with polymetabolic syndrome X. European Journal of Clinical Investigation $30871-878$.

Iimura O 1996 Insulin resistance and hypertension in Japanese. Hypertension Research 19 S1-S8.

Inoue I, Takahashi K, Katayama S, Akabane S, Negishi K, Suzuki M, Ishii J \& Kawazu S 1994 Improvement of glucose tolerance by bezafibrate in non-obese patients with hyperlipidemia and impaired glucose tolerance. Diabetes Research and Clinical Practice $\mathbf{2 5}$ 199-205.

Issemann I, Prince R, Tugwood J \& Green S 1992 A role for fatty acids and liver fatty acid binding protein in peroxisome proliferation? Biochemical Society Transactions 20 824-827.

Jones IR, Swai A, Taylor R, Miller M, Laker MF \& Alberti KG 1990 Lowering of plasma glucose concentrations with bezafibrate in patients with moderately controlled NIDDM. Diabetes Care $\mathbf{1 3}$ 855-863.

Jonkers IJ, de Man FH, van der Laarse A, Frölich M, Gevers Leuven JA, Kamper AM, Blauw G \& Smelt AH 2001 Bezafibrate reduces heart rate and blood pressure in patients with hypertriglyceridemia. Journal of Hypertension 19 749-755.

Kaikaus RM, Chan WK, Ortiz de Montellano PR \& Bass NM 1993 Mechanisms of regulation of liver fatty acid-binding protein. Molecular and Cellular Biochemistry 123 93-100.

Kaplan NM 1989 The deadly quartet. Upper-body obesity, glucose intolerance, hypertriglyceridemia, and hypertension. Archives of Internal Medicine 149 1514-1520.

Kelley DE \& Mandarino LJ 2000 Fuel selection in human skeletal muscle in insulin resistance: a reexamination. Diabetes 49 677-683.
Li Y, Higashiura K, Ura N, Torii T, Agata J, Wang L, Togashi N \& Shimamoto K 2000 Effects of the Chinese medicine, TSJN on insulin resistance and hypertension in fructose-fed rats. Hypertension Research 23 101-107.

Matsui H, Okumura K, Kawakami K, Hibino M, Toki Y \& Ito T 1997 Improved insulin sensitivity by bezafibrate in rats: relationship to fatty acid composition of skeletal-muscle triglycerides. Diabetes $\mathbf{4 6}$ 348-353.

Meertens LM, Miyata KS, Cechetto JD, Rachubinski RA \& Capone JP 1998 A mitochondrial ketogenic enzyme regulates its gene expression by association with the nuclear hormone receptor PPAR $\alpha$. EMBO Journal 17 6972-6978.

Motojima K 2000 Differential effects of PPAR $\alpha$ activators on induction of ectopic expression of tissue-specific fatty acid binding protein genes in the mouse liver. International Journal of Biochemistry and Cell Biology 32 1085-1092.

Motojima K, Passilly P, Peters JM, Gonzalez FJ \& Latruffe N 1998 Expression of putative fatty acid transporter genes are regulated by peroxisome proliferator-activated receptor $\alpha$ and $\gamma$ activators in a tissue- and inducer-specific manner. Journal of Biological Chemistry 273 16710-16714

Osumi T \& Hashimoto T 1979 Occurrence of two 3-hydroxyacylCoA dehydrogenases in rat liver. Biochimica et Biophysica Acta $\mathbf{5 7 4}$ 258-267.

Pan DA, Lillioja S, Kriketos AD, Milner MR, Baur LA, Bogardus C, Jenkins AB \& Storlien LH 1997 Skeletal muscle triglyceride levels are inversely related to insulin action. Diabetes 46 983-988.

Peeters RA, Veerkamp JH, Geurts van Kessel A, Kanda T \& Ono T 1991 Cloning of the cDNA encoding human skeletal-muscle fatty-acid-binding protein, its peptide sequence and chromosomal localization. Biochemical Journal 276 203-207.

Reaven GM 1988 Role of insulin resistance in human disease. Diabetes 37 1595-1607.

Reaven GM, Ho H \& Hoffman BB 1988 Attenuation of fructoseinduced hypertension in rats by exercise training. Hypertension 12 129-132.

Schoonjans K, Martin G, Staels B \& Auwerx J 1997 Peroxisome proliferator-activated receptors, orphans with ligands and functions. Current Opinion in Lipidology 8 159-166.

Si X, Webb RC \& Richey JM 1999 Bezafibrate, an antihypertriglyceridemic drug, attenuates vascular hyperresponsiveness and elevated blood pressure in fructose-induced hypertensive rats. Canadian Journal of Physiology and Pharmacology 77 755-762.

Smith PK, Krohn RI, Hermanson GT, Mallia AK, Gartner FH, Provenzano MD, Fujimoto EK, Goeke NM, Olson BJ \& Klenk DC 1985 Measurement of protein using bicinchoninic acid. Analytical Biochemistry 150 76-85.

Srere PA 1969 Citrate synthase. Methods in Enzymology 13 3-11.

Staels B, Dallongeville J, Auwerx J, Schoonjans K, Leitersdorf E \& Fruchart JC 1998 Mechanism of action of fibrates on lipid and lipoprotein metabolism. Circulation 98 2088-2093.

Storch J \& Thumser AE 2000 The fatty acid transport function of fatty acid-binding proteins. Biochimica et Biophysica Acta 1486 28-44.

Storlien LH, Jenkins AB, Chisholm DJ, Pascoe WS, Khouri S \& Kraegen EW 1991 Influence of dietary fat composition on development of insulin resistance in rats. Relationship to muscle triglyceride and omega-3 fatty acids in muscle phospholipid. Diabetes 40 280-289.

Su JL, Simmons CJ, Wisely B, Ellis B \& Winegar DA 1998 Monitoring of PPAR $\alpha$ protein expression in human tissue by the use of PPAR $\alpha$-specific MAbs. Hybridoma and Hybridomics 17 $47-53$.

Togashi N, Ura N, Higashiura K, Murakami H \& Shimamoto K 2000 The contribution of skeletal muscle tumor necrosis factor- $\alpha$ to insulin resistance and hypertension in fructose-fed rats. Journal of Hypertension 18 1605-1610. 
Treuner M, Kozak CA, Gallahan D, Grosse R \& Muller T 1994 Cloning and characterization of the mouse gene encoding mammary-derived growth inhibitor/heart-fatty acid-binding protein. Gene 147 237-242.

Van Nieuwenhoven FA, Verstijnen CP, Van Eys GJ, Van Breda E, De Jong YF, Van der Vusse GJ \& Glatz JF 1994 Fatty acid transfer across the myocardial capillary wall: no evidence of a substantial role for cytoplasmic fatty acid-binding protein. Journal of Molecular and Cellular Cardiology 26 1635-1647.

Veerkamp JH \& van Moerkerk HT 1993 Fatty acid-binding protein and its relation to fatty acid oxidation. Molecular and Cellular Biochemistry 123 101-106.

Wu SQ, Hopfner RL, McNeill JR, Wilson TW \& Gopalakrishnan V 2000 Altered paracrine effect of endothelin in blood vessels of the hyperinsulinemic, insulin resistant obese Zucker rat. Cardiovascular Research 45 994-1000.

Ye JM, Doyle PJ, Iglesias MA, Watson DG, Cooney GJ \& Kraegen EW 2001 Peroxisome proliferator-activated receptor (PPAR)- $\alpha$ activation lowers muscle lipids and improves insulin sensitivity in high fat-fed rats: comparison with PPAR- $\gamma$ activation. Diabetes $\mathbf{5 0}$ 411-417.

Yong QW, Thavintharan S, Cheng A \& Chew LS 1999 The effect of fenofibrate on insulin sensitivity and plasma lipid profile in non-diabetic males with low high density lipoprotein/dyslipidaemic syndrome. Annals of the Academy of Medicine, Singapore 28 778-782.

Zanotti G 1999 Muscle fatty acid-binding protein. Biochimica et Biophysica Acta 1441 94-105.

Zhang B, Marcus SL, Sajjadi FG, Alvares K, Reddy JK, Subramani S, Rachubinski RA \& Capone JP 1992 Identification of a peroxisome proliferator-responsive element upstream of the gene encoding rat peroxisomal enoyl-CoA hydratase/3-hydroxyacyl-CoA dehydrogenase. PNAS 89 7541-7545.

Received 25 February 2002

Accepted 8 April 2002 